\title{
Rapid Frequency Response From Smart Loads in Great Britain Power System
}

\author{
Diptargha Chakravorty, Student Member, IEEE, Balarko Chaudhuri, Senior Member, IEEE, \\ and Shu Yuen Ron Hui, Fellow, IEEE
}

\begin{abstract}
Flexibility in certain types of loads could be exploited to provide fast and controllable power reserve if the supply voltage/frequency is controlled using existing power electronic interfaces (e.g., motor drives) or additional ones like recently proposed electric springs. Such a load together with its power electronic interface forms a so called smart load. Effectiveness of static smart loads for primary frequency response provision has been shown in the previous papers through case studies on a segment of the low voltage/medium voltage (LV/MV) distribution network. In this paper, collective contribution of both static and motor type smart loads to rapid frequency response provision is demonstrated through a case study on the Great Britain (GB) transmission system. The active power reserve available from such smart loads are quantified and aggregated at each node at the transmission level $(275 / 400 \mathrm{kV})$. The study shows that the smart loads collectively offer a short-term power reserve which is comparable to the spinning reserve in the GB system, and thus can ensure acceptable frequency deviation and its rate of change following a large infeed loss.
\end{abstract}

Index Terms-Demand response, electric spring, primary reserve, rapid frequency response, smart load.

\section{NOMENCLATURE}

$\begin{array}{cl}\text { Acronyms } & \\ \text { NSG } & \text { Non-synchronous generator } \\ \text { RFR } & \text { Rapid frequency response } \\ \text { RoCoF } & \text { Rate of change of frequency } \\ \text { IM } & \text { Induction motor } \\ \text { SL } & \text { Smart load } \\ \text { ES } & \text { Electric spring } \\ \text { NCL } & \text { Non-critical load } \\ \text { SSL } & \text { Static smart load } \\ \text { MSL } & \text { Motor smart load. }\end{array}$

Manuscript received August 25, 2015; revised November 5, 2015; accepted November 29, 2015. Date of publication April 6, 2016; date of current version August 21,2017. This work was supported in part by the Engineering and Physical Science Research Council, U.K., under Autonomic Power Systems Grant EP/I031650/1, and in part by the Hong Kong Research Grant Council under Theme-Based Project T23-701/14-N. Paper no. TSG-00998-2015.

D. Chakravorty and B. Chaudhuri are with the Department of Electrical and Electronic Engineering, Imperial College London, London SW7 2AZ, U.K. (e-mail: d.chakravorty12@imperial.ac.uk; b.chaudhuri@imperial.ac.uk).

S. Y. R. Hui is with the Department of Electrical and Electronic Engineering, Imperial College London, London SW7 2AZ, U.K., and also with the Department of Electrical and Electronic Engineering, University of Hong Kong, Hong Kong (e-mail: r.hui@imperial.ac.uk). Supporting data is available on request: please contact cappublications@imperial.ac.uk.

Color versions of one or more of the figures in this paper are available online at http://ieeexplore.ieee.org.

Digital Object Identifier 10.1109/TSG.2016.2517409

\author{
Symbols \\ $P_{S L}, Q_{S L} \quad$ SL active and reactive power \\ $P_{E S}, Q_{E S} \quad \mathrm{ES}$ active and reactive power \\ $P_{N C}, Q_{N C}$ NCL active and reactive power \\ $V_{C} \quad$ Supply mains voltage \\ $V_{N C} \quad$ Voltage across NCL \\ $V_{E S} \quad$ ES injected voltage \\ $\theta_{E S} \quad$ Angle of $V_{E S}$ \\ $\triangle P_{S L} \quad$ SL p.u. active power reserve \\ $\triangle Q_{S L} \quad$ SL p.u. reactive power reserve \\ $k p v, k q v \quad$ NCL active and reactive power voltage expo- \\ nents \\ $k p f, k q f \quad$ IM active and reactive power frequency expo- \\ nents \\ $P_{\text {in }} \quad$ IM active power input.
}

\section{INTRODUCTION}

$\mathbf{I}$ NCREASING penetration of non-synchronous generators (e.g., wind, PV etc.) would result in drastic reduction of the system (effective) inertia in future [1]. Moreover, the possibility of larger and more frequent in-feed losses is likely to cause unacceptably large variations in grid frequency and it's rate of change (RoCoF). Restricting RoCoF within acceptable limits will be critical to avoid triggering of mains protection relays based on RoCoF which could lead to cascaded problems and threaten system security [2].

Non-Synchronous generators (NSGs) like wind farms could be made to contribute 'synthetic inertia' [1] through appropriate modification in converter control although there are certain challenges in extracting rapid frequency response (RFR) from offshore wind farms connected through HVDC link [1]. There is increasing focus on collective participation of loads in grid frequency regulation under the Demand Side Management (DSM) or Demand Response (DR) framework [3]-[5]. DR is typically exercised either through load scheduling based on price signals [6] or scheduling of delay tolerant loads or through direct on/off control of thermostatic loads like refrigerator and freezers [7]-[9]. Other options include loads with energy storage like electric vehicles (EV) which can be used in vehicle to grid (V2G) control mode to provide frequency regulation service [10]. Efforts have been made to draw synergy between EV charging and wind power scheduling [11]. This can help mitigate the intermittency problem by using EV as demand response. Primary frequency support through grid level storage like Battery Energy 
Storage System (BESS) has been studied in [12] and [13]. However, cost and life span of battery storage remains an issue.

Most of the conventional demand response methods, with the exception of thermostatic loads, are tailored for peak shaving, peak load deferring. On/off control of thermostatic loads reduce the average power consumption thereby, provide grid frequency support in shorter time scales. However, on/off control can not be used for several other kinds of load like lighting, large motors etc where the proposed smart load concept could be useful. A smart load (SL) is a combination of a non-critical load (which can tolerate wider voltage/frequency variations for a short period of time) and a power electronic interface which decouples the load from the supply. Such decoupling allows the voltage/frequency across the load to be controlled over a wider range to derive some short-term power reserve according to their voltage (for static loads) or frequency (for motor loads) dependence.

Smart loads (static smart loads) require capital investment in power electronic interface and also incurs power losses. In certain cases, it could be more appropriate (economically and otherwise) to deploy one power electronic compensator to control a cluster of similar non-critical loads (e.g., supply to an array of street lights or cluster of lighting loads in a large commercial building). Most smart loads are not necessarily in continuous operation over 24 hour period. Thus the power reserve available from smart loads would vary depending on the time of operation of specific load types. It is important to note that power reserve from smart loads would be complemented by the reserve available from other sources like thermostatic loads or BESS.

The concept of series compensator (Electric Spring) based smart load was first proposed in [14] followed by several other papers on dynamic modeling [15], performance analysis [16], [17] and control [18], [19]. In [20] distributed voltage control capability of smart load has been compared against STATCOM while [21] demonstrate the effectiveness of smart loads in primary frequency control considering only a segment of the MV/LV network.

In this paper, we present a realistic case study on the Great Britain (GB) transmission system to quantify the collective contribution of several smart loads spread around the system. Many such smart loads would contribute collectively to rapid frequency control by reacting to the local frequency measurement. It has been established analytically that a 'fully decentralized' control of several (potentially millions) loads based on locally measured frequency can optimally contribute to primary frequency control without requiring any coordination/communication [22], [23]. Apart from implicit coordination through droop control [18], it is not necessary to coordinate the efforts of multiple smart loads using a centralized controller.

The scope of this paper includes systematic classification of GB system industrial and service sector loads as potential smart load candidates using actual load data for 2013 (available from Department of Energy and Climate Change [24]). Domestic sector has not been considered as this study focuses on the application of SL with large/bulk loads offering higher

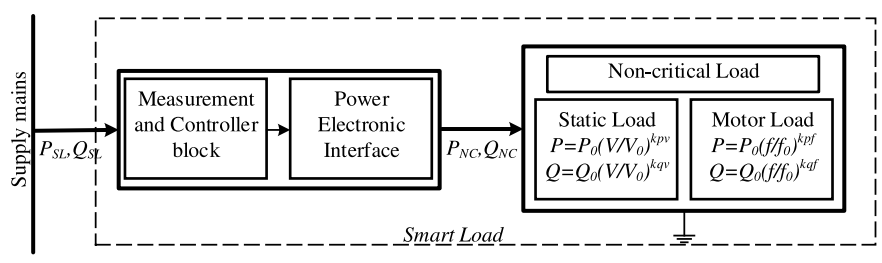

Fig. 1. Smart load concept.

load factors instead of individual high power household appliances. The paper is broadly divided into two parts: estimation of short-term power reserve available from the smart loads and time domain simulation to asses the aggregated impact of smart loads on grid frequency regulation and improvement in RoCoF. Power reserve from candidate loads in the GB system is estimated separately from static and motor type loads with conservative figures for different uncertain parameters like load factor and supply voltage at each bus etc. For the time domain simulation the power reserve offered by the candidate smart loads are aggregated at each node at the transmission level $(275 / 400 \mathrm{kV})$ while the remaining loads are represented by their exponential model along with natural frequency dependence.

Case studies on the GB system show that smart loads are able to ensure acceptable frequency deviation and its rate of change (RoCoF) following a large infeed loss. Only high power loads in the industrial and service sector are considered in this study which can be extended to domestic loads as well. Despite all the variability and uncertainty associated with accurate load representation and distribution, this paper shows the potential of smart loads in ensuring secure operation of future low-inertia systems which are likely to experience larger and more frequent infeed losses.

\section{SMART LOAD}

\section{A. Concept}

Certain loads can tolerate a wider range of variation in the supply voltage/frequency for short time without any disruption to consumers. Such loads are henceforth referred to as noncritical loads (NCL). A smart load (SL) is a combination of a non-critical load (or a cluster of similar non-critical loads) and a power electronic interface which decouples the load from the supply. This way power consumption of the load can be controlled for short duration based on its voltage (for static loads) or frequency (for motor loads) dependence.

Use of impedance-type smart loads has been demonstrated in previous papers [16], [17]. This paper further generalizes the concept by introducing other types of static smart loads and also includes the option of drive connected motor loads. A general schematic of the smart load concept is shown in Fig. 1. The non-critical load is represented using an exponential model. The compensator consists of the measurement and control block together with the converter (Electric Spring) in case of static smart load (SSL), while for motor smart load (MSL) it is the drive unit itself. 


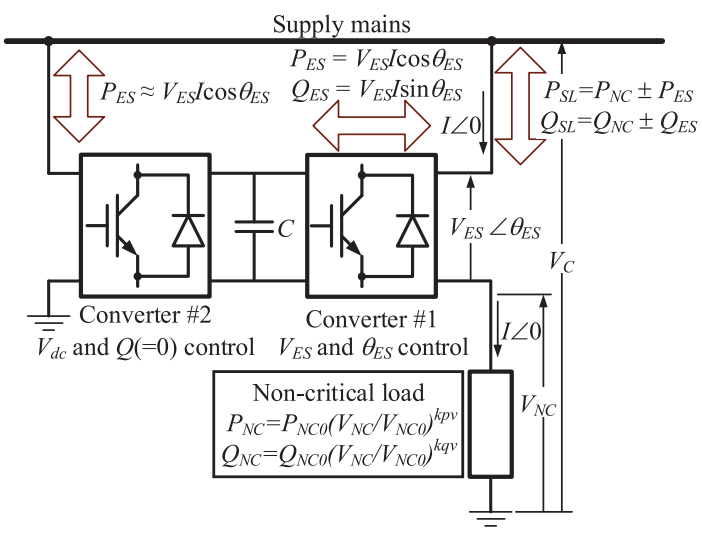

Fig. 2. Smart load with series-parallel converter.

\section{B. Static Smart Load (SSL)}

A static smart load (SSL) is formed by inserting a part rated power electronic compensator in series between the supply and a non-critical static load (e.g., heaters, lighting loads) which can tolerate a wider variation in voltage for a short time. In response to variations in the measured supply voltage and/or grid frequency, the compensator injects a voltage to regulate the supply voltage while controlling the voltage across the load and hence, its power consumption to collectively contribute towards frequency support. Thus a SSL act as controllable active $(P)$ and reactive $(Q)$ power sink providing fast short-term power reserve (FSPR). The $P-Q$ capability of a SSL depends on the type of the non-critical load (e.g., voltage dependence, power factor), permissible voltage variation across it and other factors described later in the paper. A typical SSL arrangement is shown in Fig. 2 which is similar to a Unified Power Quality Conditioner (UPQC).

The compensator in series with the non-critical load (converter \#1) is set to control the magnitude $\left(V_{E S}\right)$ and phase angle $\left(\theta_{E S}\right)$ of the injected voltage. The other converter (\#2) maintains the dc link voltage $\left(V_{d c}\right)$ and thus, exchange the active power $\left(P_{E S}\right)$ of the series converter (\#1) with the supply mains. To reduce the apparent power rating of the parallel converter (\#2) it can be operated at unity power factor (i.e., no reactive power exchange). The total active $\left(P_{S L}\right)$ and reactive $\left(Q_{S L}\right)$ power consumption of the smart load is the sum of non-critical load power and compensator power. However, the active power supplied (consumed) by the series converter is equal (neglecting losses) to the power consumed (supplied) by the parallel converter from the supply mains. Hence, SSL active power consumption is expected to be equal to that of non-critical load (i.e., $P_{S L}=P_{N C}$ ). Although quite flexible, such a series-parallel converter arrangement is more suitable for high power loads or cluster of loads in the industrial and service sectors. Similar types of NCLs (e.g., lighting loads in a large commercial building) can be supplied through a single series-parallel converter configuration.

1) Control of SSL: The control loop for a SSL is shown in Fig. 3. Deviation $(\Delta f)$ of measured frequency $\left(f_{\text {meas }}\right)$ from its reference value $\left(f_{\text {ref }}\right)$ is used to determine the change in active power $\left(P_{\Delta f}\right)$ corresponding to governor action. Droop gain

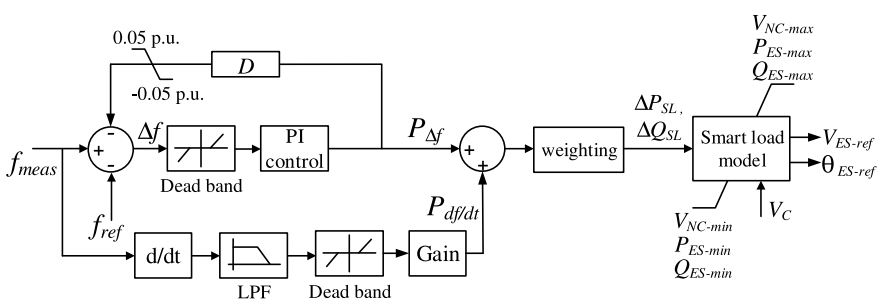

Fig. 3. Control of static smart load for grid frequency support.
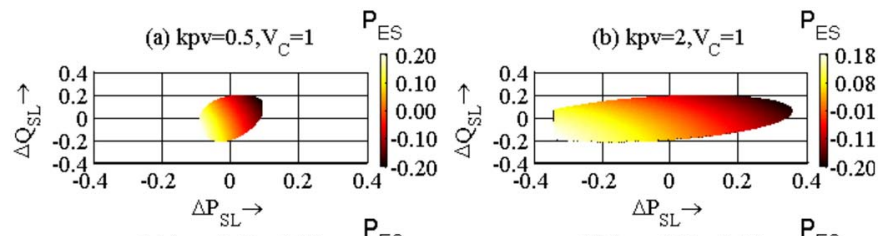

(c) $\mathrm{kpv}=2, \mathrm{~V}_{\mathrm{C}}=0.95 \quad \mathrm{P}_{\mathrm{ES}}$

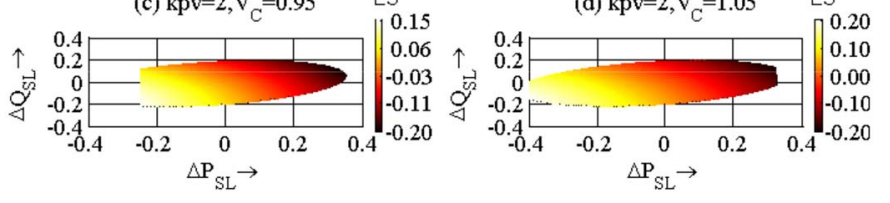

Fig. 4. $P-Q$ capability of static smart loads (SSL) for different voltage exponents $k p v$ and supply/mains voltage $V_{C}$ (a) $k p v=0.5, V_{C}=1$ (b) $k p v=2$, $V_{C}=1$ (c) $k p v=2, V_{C}=0.95$ (d) $k p v=2, V_{C}=1.05$.

$(D)$ is used to update the frequency reference $\left(f_{\text {ref }}\right)$ within the allowed limits of $\pm 0.05 \mathrm{pu}$. A second loop uses the measured RoCoF to provide a power term which mimics the inertial contribution $\left(P_{d f / d t}\right)$. Sum of these two power terms is weighted according to the $R / X$ ratio of the network to derive the required change in active $\left(\Delta P_{S L}\right)$ and reactive $\left(\Delta Q_{S L}\right)$ power consumption of the SSL. The smart load model uses $\Delta P_{S L}, \Delta Q_{S L}$ and the measured supply voltage $V_{C}$ to calculate the reference voltage magnitude $\left(V_{E S-r e f}\right)$ and phase angle $\left(\theta_{E S-r e f}\right)$ for converter\#1. Appropriate limits on permissible variation in non-critical load voltage $\left(V_{N C-\min }, V_{N C-\max }\right)$, active $\left(P_{E S-\min }\right.$, $\left.P_{E S-\max }\right)$ and reactive power $\left(Q_{E S-\min }, Q_{E S-\max }\right)$ of the compensator are imposed within the smart load model.

2) Active and Reactive Power Capability: A SSL acts as a controllable active $(P)$ and reactive $(Q)$ sink by exerting control over the injected voltage magnitude $V_{E S}$ and phase angle $\theta_{E S}$. Its capability depends on the type of non-critical load, supply/mains voltage $\left(V_{C}\right)$ and the limitations imposed by the converter power rating and maximum permissible variation in non-critical load voltage $\left(V_{N C}\right)$. Fig. 4 shows the $P-Q$ capability of SSL for different values of $k p v$ and $V_{C}$ keeping $k q v$, load power factor and converter rating fixed.

The rating required for individual electric spring would depend on how many of these are deployed across the system and also at which level (high power loads at MV or low power domestic loads at LV level). This has to be considered on a case by case basis. For the case study reported in this paper, the apparent power rating of the series converter $\left(S_{E S}\right)$ is limited to $20 \%$ of the corresponding non-critical load for the nominal case. As this $20 \%$ is chosen somewhat arbitrarily, a rigorous sensitivity analysis is presented in Fig. 10 (d) to show the impact of using different converter ratings on available power reserve. 


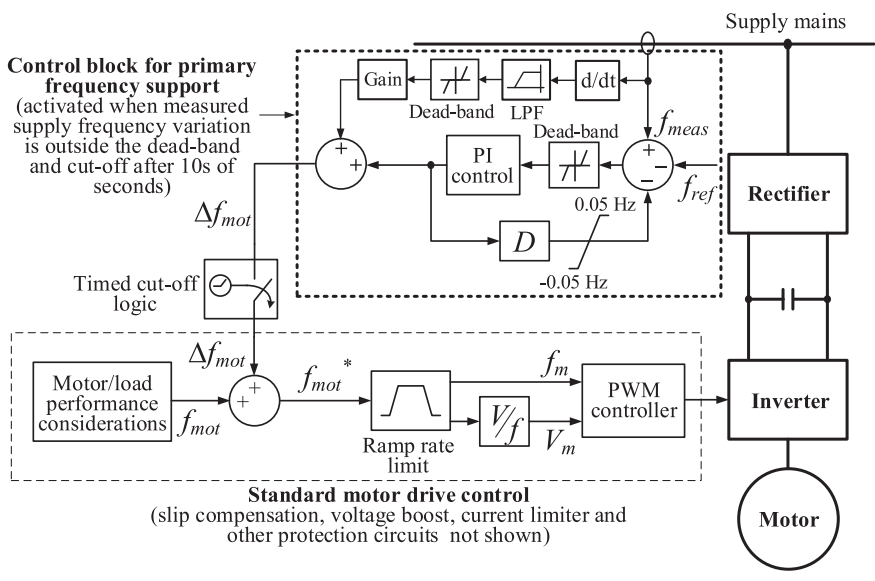

Fig. 5. Motor type smart load with modified drive control.

Range of these capability curves are primarily limited by the rating of the converter and permissible variation in voltage $\left(V_{N C}\right)$ across the non-critical load. In this study the shortterm variation in $V_{N C}$ is limited to $\pm 20 \%$. In practice, the voltage tolerance could be tighter depending on the type of the load which would result in less overall reserve than what is demonstrated later in the paper. Nonetheless, the collective contributions of SLs could play a major role in reducing the requirement of fast reserve provision from energy storage etc. The $P-Q$ capability covers all four quadrants enabling any possible combination of change in active and reactive power consumption. The capability zone is clipped on one side $\left(-\Delta P_{S L}\right.$ axis) due to the constraint on the lower limit of the non-critical load voltage $\left(V_{N C}>0.8 \mathrm{pu}\right)$. However, the effect on the upper limit of the non-critical load voltage $\left(V_{N C}<1.2\right.$ $\mathrm{pu})$ is not visible here as the converter rating limit is reached before the non-critical load voltage limit.

For higher supply/mains voltage, the capability of SSL increases in all four quadrants. Fig. 4(c)\&(d) shows two different operating conditions for a constant impedance type $(k p v=2)$ non-critical load. For $V_{C}=0.95$ pu, the capability is limited to around $0.2 \mathrm{pu}$ along $-\Delta P_{S L}$ axis due to the lower limit of $V_{N C}$. The capability increases for a supply/mains voltage of $V_{C}=1.05 \mathrm{pu}$. In this case, the converter rating limits the capability of the SL along $-\Delta P_{S L}$ axis.

\section{Motor Smart Load (MSL)}

Substantial proportion of industrial and service sector loads are induction motors. Directly connected motors inherently provide inertial response to the system unlike the drivecontrolled motors which are decoupled from the supply. Adjustable speed drives (ASD) are used to control the speed of the motor for improved performance and better energy utilization. With subtle modification to the controller, as shown in Fig. 5, it is possible to use the existing motor drives to control the power consumption of the motors over a short-time and thereby, contribute to rapid frequency response when needed. The proposed modification includes a df/dt loop to provide inertial response within the ramp rate limits. (a) small motor (5HP)

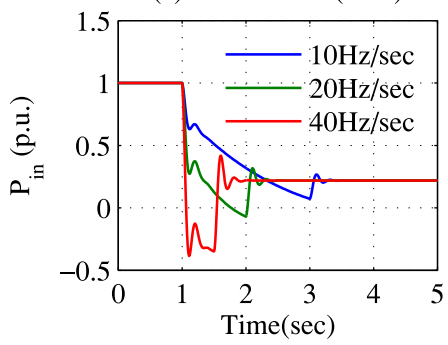

(b) large motor (200 HP)

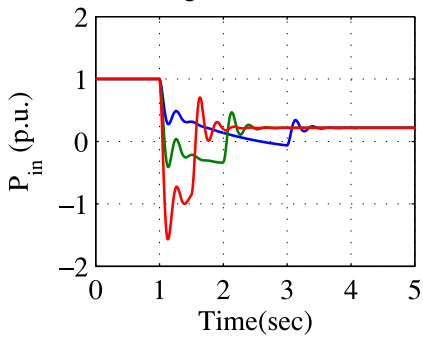

Fig. 6. Dynamic response of small and large induction motors.

The additional frequency support block is introduced along with the standard drive control. Measured deviation in grid frequency and RoCoF is used to modify the supply frequency reference for the motor. A dead band is used to limit the inertial response below a predefined setting to avoid negative impact during the frequency recovery period. The summation of the two correction signals determine $\Delta f_{\text {mot }}$ for modifying the motor drive frequency set point $\left(f_{m o t}\right)$. The $\Delta f_{m o t}$ signal should have a timed cut-off logic (which could be tens of seconds) to avoid disrupting the steady performance of the motor. The rate of change of the motor frequency reference in response to the measured grid frequency variation has to be limited to avoid excessive regeneration especially, for drives with passive front-end.

Fig. 6 shows the dynamic response of two types of industrial motor when the drive frequency is reduced from $50 \mathrm{~Hz}$ to $30 \mathrm{~Hz}$ following three different ramp rates. For similar ramp rate the amount of regenerated power is significantly high for a large motor. This may not be a major concern if the drive has active front end. But for passive front end drives, this might not be acceptable. Fig. 6(b) shows that a ramp rate of $40 \mathrm{~Hz} / \mathrm{sec}$ for a large induction motor will lead to regenerated power larger than the nominal rating of the motor. Therefore, for practical purposes the ramp rate is limited to about $20 \mathrm{~Hz} / \mathrm{sec}$ [25]. The settling time for large induction motor is found to be around $1.8 \mathrm{sec}$ corresponding to $20 \mathrm{~Hz} / \mathrm{sec}$. This is represented in the simulation model by introducing a first order time lag.

The above mentioned control scheme will enable a MSL to contribute to rapid frequency response by changing the active power consumption of the motor according to the measured grid frequency and RoCoF. A drive controlled motor operating at a certain frequency (e.g., $45 \mathrm{~Hz}$ ) would respond to an under-frequency event by reducing its operating frequency (e.g., down to $30 \mathrm{~Hz}$ ) for a few seconds. For over-frequency events, the motors would enter the constant-power mode beyond $50 \mathrm{~Hz}$ as $V / f$ ratio is no longer maintained [25]. In such cases, the frequency support loop is disabled and the motor operates with standard drive control.

Induction motor drives can have either active front end or passive front end. While active front end provides more flexibility and the option for slip power recovery, it increases the cost of the drives significantly. So passive front end (diode) is commonly used in most drives applications. A passive front end appears to be a near unity power factor load making the MSL a controllable active power sink. 


\section{RESERVE CALCULATION}

Active power reserves available from SSL and MSL have to be aggregated at the transmission level $(275 / 400 \mathrm{kV})$ to estimate the system-wide reserve and asses their collective impact for system frequency support. Capability of individual SLs depend on the supply/mains voltage apart from other factors like load type, power factor, converter rating etc. Voltage at each node of the MV/LV network would be different based on the network loading and tap position at the primary substation during different time of the day (e.g., daily variation, seasonal variation etc.) leading to different capability of individual SLs. For analytically estimating and aggregating the available power reserve it is assumed that each node of the $\mathrm{MV} / \mathrm{LV}$ network is maintained at a minimum of $0.95 \mathrm{pu}$. This assumption provides a conservative estimate of power reserve for small industrial and commercial customers which, in the U.K., are typically supplied through short cables [26].

\section{A. SSL Reserve Calculation}

The power consumption of the non-critical load at any particular voltage $V_{N C}$ is calculated using (1). This value of $P_{N C}$ and $Q_{N C}$ is used in (2) to find the consumption of the smart load as a whole. The difference between the nominal consumption $\left(P_{S L 0}\right)$ and the actual consumption $\left(P_{S L}\right)$ provides the smart load power reserve, as in (3). However, there can be multiple solutions of $Q_{E S}$ for a specific value of $\Delta P_{S L}$ which results in SSL capability spanning over a region (Fig. 4). The maximum power reserve ( $\triangle P_{S L}$ for under-frequency event) for SSL can be obtained from the $P-Q$ capability curve assuming $V_{C}=0.95 \mathrm{pu}, \pm 20 \%$ relaxation of $V_{N C}$ and the converter rating limited to $20 \%$ of the non-critical load.

$$
\begin{aligned}
P_{N C} & =P_{N C 0}\left(\frac{V_{N C}}{V_{N C 0}}\right)^{k p v}, Q_{N C}=Q_{N C 0}\left(\frac{V_{N C}}{V_{N C 0}}\right)^{k q v} \\
P_{S L} & =P_{N C} \pm P_{E S}, Q_{S L}=Q_{N C} \pm Q_{E S} \\
\Delta P_{S L} & =P_{S L}-P_{S L 0}, \Delta Q_{S L}=Q_{S L}-Q_{S L 0} .
\end{aligned}
$$

\section{B. MSL Reserve Calculation}

Active power consumption of induction motors driving centrifugal loads is highly sensitive to supply frequency. To represent such motor loads in exponential form the power-frequency sensitivity exponent ( $k p f$ ) should be calculated. Steps for calculation of $k p f$ include solving the induction motor equivalent circuit equations using electrical and mechanical parameters. Solutions were obtained by sweeping the stator supply frequency over a range while maintaining $V / f$ ratio constant. The solution provides motor slip $(s)$ corresponding to each supply frequency which is then used to calculate the active power $\left(P_{i n}\right)$ consumption of the induction motor using $(4),(5)$. The slope of the active power consumption with respect to stator frequency variation provides the $k p f$ values. Symbol $D$ stands for denominator of (4) which is expanded in (5).

$$
\begin{aligned}
& P_{i n}=\frac{1}{D}\left(\left(V_{i n} X_{m}\right)^{2} R_{r} \frac{(1-s)}{s}+\left(V_{i n} X_{m}\right)^{2} R_{r}\right. \\
& \left.+V_{i n}^{2} R_{s}\left(\left(\frac{R_{r}}{s}\right)^{2}+\left(X_{r}+X_{m}\right)^{2}\right)\right)
\end{aligned}
$$

$$
\begin{aligned}
D= & \left(R_{s} \frac{R_{r}}{s}-X_{s}\left(X_{m}+X_{r}\right)-X_{m} X_{r}\right)^{2} \\
& +\left(R_{s}\left(X_{m}+X_{r}\right)+R_{r} \frac{X_{s}+X_{m}}{s}\right)^{2}
\end{aligned}
$$

Here $R_{s}, X_{S}$ stands for stator resistance and reactance, $X_{m}$ is magnetizing reactance, $R_{r}, X_{r}$ are rotor resistance and reactance and $V_{i n}$ is the IM input voltage.

The induction motor drives have a minimum operating frequency which varies for different applications. In absence of precise information, a conservative figure of $30 \mathrm{~Hz}$ was assumed as the lower limit for all motor types. In response to grid frequency deviation, the drive frequency set point would be reduced to $30 \mathrm{~Hz}$. Apart from the lower limit of frequency and the sensitivity exponent $(k p f)$, power reserve from a MSL depends on the operating frequency of a particular motor at the time of disturbance. This means that a motor operating at $50 \mathrm{~Hz}$ at the time of disturbance will offer more power reserve compared to another motor operating at $40 \mathrm{~Hz}$, assuming similar lower frequency limit and sensitivity exponent.

In this study, the operating frequencies of the motors were assumed to be normally distributed with a mean value of $50 \mathrm{~Hz}$ and a standard deviation of $3 \mathrm{~Hz}$. In Section IV-H, results of sensitivity analysis with different values of standard deviation and the minimum operating frequency are presented. By considering the $\mathrm{y}$ axis of the cumulative distribution function (CDF) as percentage of motors connected to a busbar, we can account for $100 \%$ of motors. Corresponding to each operating frequency from the distribution, the power reserve values are calculated and added up to find the total power reserve $\left(\Delta P_{S L}\right)$ available from a specific type of MSL at a particular node, using (6).

$$
\Delta P_{S L}=\frac{\sum_{i} P_{0}\left[\left(\frac{f_{i}}{f_{0}}\right)^{k p f}-\left(\frac{f_{d r}}{f_{0}}\right)^{k p f}\right]}{\sum_{i} P_{0}}
$$

In (6), $f_{i}$ corresponds to random operating frequency at the time of disturbance and $f_{d r}$ stands for minimum permissible drive frequency, which in this case is assumed to be $30 \mathrm{~Hz}$. Motors operating above $50 \mathrm{~Hz}$ at the time of disturbance do not contribute to frequency response immediately as those are in constant power mode. Their speed is reduced below nominal frequency before they start contributing.

\section{CASE STUdy}

In order to evaluate the effectiveness of static and motor smart loads for grid frequency regulation, a case study was carried out on the 37-bus reduced equivalent model of Great Britain transmission network. Alongside the base case (with present inertia level) a future low inertia scenario was also considered.

\section{A. Great Britain (GB) Transmission System}

The reduced equivalent model of the Great Britain (GB) transmission system, shown in Fig. 7, consists of 53 synchronous machines and 14 asynchronous machines (wind and marine). There are 37 zones each of which is represented by 


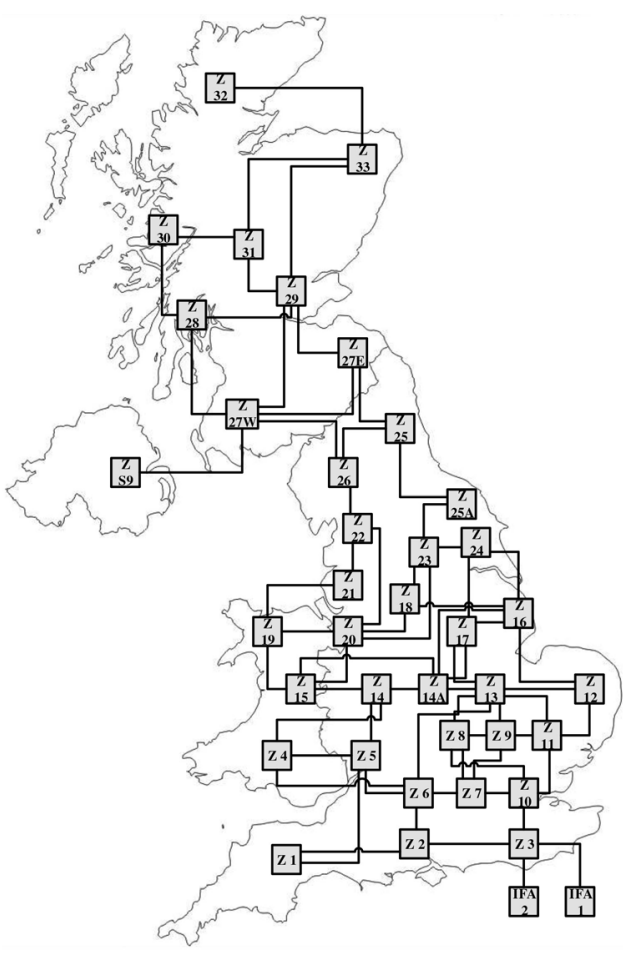

Fig. 7. Reduced equivalent of Great Britain Transmission System with 37 zones.

equivalent generators, shunt devices and loads connected to a bus. Each of these loads are split into critical (sensitive) and non-critical loads according to the actual GB load classification data (discussed later in the paper). The non-critical loads are operated as smart loads. The critical loads are represented by exponential model with frequency dependence. Active and reactive power components of the critical loads are considered to be constant current type and constant impedance type, respectively [27], [28].

\section{B. Service and Industry Sector Loads in Great Britain (GB)}

The annual electricity consumption across different sectors and sub-sectors in GB was used to estimate the power reserve available from the smart loads. Recent data published by the Department of Energy and Climate Change (DECC) for year 2013 [24] (table 1.07) shows that the total electricity consumption in GB was 26375 ktoe (i.e., 306.74 TWh). The overall consumption is split between the domestic, service, industry and transport sectors. Domestic sector $(37 \%)$ is found to be the largest consumer while industry (30\%) and service (32\%) sector has almost equal share. Transport sector (non-heat purposes) accounts for only $1 \%$ at present but is expected to have a larger share in future.

The scope of this paper is restricted to only industrial and service sector loads which can be classified into different categories based on their specific applications like space heating, lighting etc. Out of the different categories listed in [24] (table 1.07), there are certain types like cooking/catering and computing which are not suitable candidates for smart load and are excluded from reserve estimation. Table I shows the
TABLE I

SERVICE ANd INDUSTRy SECtor LoAds IN Great Britain (GB)

\begin{tabular}{|c|c|c|c|c|c|c|}
\hline $\begin{array}{l}\text { Load } \\
\text { Sector }\end{array}$ & $\begin{array}{c}\text { Load } \\
\text { Category }\end{array}$ & $\%$ & $\begin{array}{c}\text { Load } \\
\text { Subcategory }\end{array}$ & $\%$ & $\mathbf{L F}^{1}$ & $\begin{array}{c}\text { Capacity } \\
\text { (GW) }\end{array}$ \\
\hline \multirow{6}{*}{$\begin{array}{l}\text { Service } \\
(32 \%)\end{array}$} & Space heating & 14 & & 100 & 0.6 & 2.65 \\
\hline & Water heating & 4 & & 100 & 0.6 & 0.76 \\
\hline & Cooling/ ventilation & 9 & & 100 & 0.6 & 1.71 \\
\hline & \multirow{2}{*}{ Lighting } & \multirow{2}{*}{41} & Fluorescent & 49 & 0.6 & 3.81 \\
\hline & & & Halogen & 51 & 0.6 & 3.96 \\
\hline & Other/ critical & 32 & & 100 & 0.6 & 6.06 \\
\hline \multirow{11}{*}{$\begin{array}{l}\text { Industry } \\
(30 \%)\end{array}$} & Space heating & 8 & & 100 & 0.8 & 1.07 \\
\hline & Drying/ separation & 7 & & 100 & 0.8 & 0.93 \\
\hline & \multirow{2}{*}{ Industrial motor } & \multirow{2}{*}{32} & Large motor & 50 & 0.8 & 2.13 \\
\hline & & & Small motor & 50 & 0.8 & 2.13 \\
\hline & Compressed air & 9 & & 100 & 0.8 & 1.20 \\
\hline & \multirow{4}{*}{ Lighting } & \multirow{4}{*}{3} & Mercury $\mathrm{HP}^{2}$ & 6 & 0.8 & 0.02 \\
\hline & & & Sodium $\mathrm{HP}^{2}$ & 58 & 0.8 & 0.23 \\
\hline & & & Sodium $\mathrm{LP}^{3}$ & 2 & 0.8 & 0.01 \\
\hline & & & Other & 34 & 0.8 & 0.14 \\
\hline & Refrigeration & 6 & & 100 & 1 & 0.64 \\
\hline & Other/ critical & 35 & & 100 & 0.8 & 4.66 \\
\hline \multicolumn{6}{|c|}{ Total installed capacity of loads } & 32.12 \\
\hline
\end{tabular}

share of different types of loads for the industry and service sector in GB.

Lighting load is found to have the largest share (41\%) within the service sector while motor loads dominate the industrial sector accounting for about $32 \%$ of the total load. Motors ranging from $5 \mathrm{HP}$ to $200 \mathrm{HP}$ and above are part of this category. Loads having specific applications like space heating, compressed air, refrigeration etc. are also motor type loads which are shown separately. For both sectors, loads which are not non-critical are clubbed within the 'other' category including high/low temperature process, cooking/catering, computing etc.

Industrial and service sector loads can be broadly classified into three groups: (a) static, (b) motor and (c) thermostatic loads. Non-motor loads like lighting, computer, cooking etc. qualify as static type, while all temperature controlled loads like refrigeration, cooling and ventilation etc. fall under thermostatic type. The purpose of this classification is to figure out the appropriate mechanism of extracting rapid frequency response from these loads, the options being (a) continuous control of non-critical load voltage in SSL framework, (b) continuous control of motor supply frequency in MSL framework and (c) on-off control. While on-off control typically offers maximum power reserve and is effective for thermostatic loads (due to thermal inertia), it is not necessarily feasible/suitable for several load types (e.g., lighting, industrial motor).

In recent years, cooling/airconditioning type thermostatic loads have shifted from directly connected motors to adjustable speed drive systems [29], [30] which offers the option of operating those as MSL for rapid frequency response while using on-off control over longer time scales.

\section{Static Smart Load (SSL) Candidates}

Industrial and service sector loads presented in Table I are segregated into static and motor type loads. The candidate static loads within the two sectors are presented in Table II. Static load is mostly dominated by lighting load and this can be attributed to the high percentage of lighting load in service sector $(41 \%)$ compared to only $3 \%$ in industry. This calls 
TABLE II

Static Smart LoAd (SSL) CANDidates

\begin{tabular}{|c|c|c|c|c|c|}
\hline \multirow{3}{*}{$\begin{array}{c}\text { Load } \\
\text { Sector }\end{array}$} & \multirow{2}{*}{$\begin{array}{c}\text { Load } \\
\text { Category }\end{array}$} & $\begin{array}{c}\text { Installed } \\
\text { Capacity }\end{array}$ & $\begin{array}{c}\text { SSL } \\
\text { capacity }\end{array}$ & \multicolumn{2}{c|}{$\begin{array}{c}\text { SSL } \\
\text { reserve }\end{array}$} \\
\cline { 3 - 6 } & & $(\mathrm{GW})$ & $(\mathrm{GW})$ & $($ p.u. $)$ & $(\mathrm{GW})$ \\
\cline { 3 - 6 } & & $(\mathrm{a})$ & $(\mathrm{b})$ & $(\mathrm{c})$ & $(\mathrm{d})$ \\
\hline \hline \multirow{3}{*}{ Service } & Water heating & 0.76 & 0.76 & 0.26 & 0.20 \\
\cline { 2 - 6 } & Fluorescent light & 3.81 & 3.31 & 0.14 & 0.46 \\
\cline { 2 - 6 } & Halogen light & 3.96 & 3.45 & 0.22 & 0.76 \\
\hline \multirow{5}{*}{ Industrial } & Mercury HP light & 0.02 & 0.02 & 0.29 & 0.01 \\
\cline { 2 - 6 } & Sodium HP light & 0.23 & 0.23 & 0.3 & 0.07 \\
\cline { 2 - 6 } & Sodium LP light & 0.01 & 0.01 & 0.08 & 0.00 \\
\cline { 2 - 6 } & Fluorescent light & 0.14 & 0.14 & 0.14 & 0.02 \\
\cline { 2 - 6 } & Drying/separation & 0.93 & 0.93 & 0.26 & 0.24 \\
\hline \multicolumn{2}{|c|}{ Total static load } & $\mathbf{9 . 8 6}$ & $\mathbf{8 . 8 5}$ & & $\mathbf{1 . 7 6}$ \\
\hline
\end{tabular}

for further classification of service sector lighting load [31] (table 5.14). Retail is found to have the largest share (35\%). Essential public services like health and other emergency sectors have been excluded from this study. Hence, out of the total service sector lighting load $87 \%$ was considered for smart load application. Solid state lighting loads like LEDs can tolerate a wider variation in supply voltage and are therefore, ideal candidates for smart load application [32]. However, the U.K. service and industrial sector in 2013 was dominated by HID lamps with negligible share of LED lighting. In future, proportion of LED lighting is expected to increase and it could then constitute a significant part of the total reserve. For example, [31] suggests that the entire fleet of street lighting in the U.K. (about $1.5 \mathrm{GW}$ ) could potentially use LED in future which would provide significant power reserve with virtually no disruptive effect.

In Table II column (b) represents $87 \%$ of installed capacity (column (a)) for service sector lighting load and 100\% of all other loads. Figures in column (c) are obtained from Table III based on the calculation method presented in Section III-A. The figures in column (d) show the available reserves in absolute units $(\mathrm{GWs})$ which are obtained by multiplying the per unit reserve in column (c) with the corresponding smart load capacity in column (b).

Power reserve from lighting loads within different subsectors depend on the type of lighting which determines the exponent kpv. From [31] (table 5.18), it can be seen that service sector lighting essentially consists of energy efficient fluorescent (49\%) and halogen (51\%) type lamps in almost equal proportion. Similarly, lighting load in the industrial sector can be broadly divided into four categories [31] (table 5.18) whose percentage contribution are shown in Table I. These lamps have a very strong dependence to voltage change and requires relatively high minimum voltage (switch-off voltage) to avoid flickering or turning off. The switch off voltages for different types of HID lamps [33] suggest that 20\% reduction in terminal voltage is well within the acceptable limit.

\section{Power Reserve From Static Smart Loads (SSL)}

For each type of static load, typical exponent values $(k p v, k q v)$ and power factors $(p f)$, obtained from [33]-[36] are summarized in Table III. The calculated power reserves, following the method introduced in Section III-A, are listed in Table III.
TABLE III

Static Smart Load Exponents and Calculated Power Reserve

\begin{tabular}{|l|c|c|c|c|}
\hline Load Type & $p f$ & $k p v$ & $k q v$ & Power reserve (p.u.) \\
\hline \hline Drying & 1 & 1.95 & 0 & $\mathbf{0 . 2 6}$ \\
\hline Water heating & 1 & 2 & 0 & $\mathbf{0 . 2 6}$ \\
\hline Fluorescent & 0.9 & 1 & 3 & $\mathbf{0 . 1 4}$ \\
\hline Halogen & 1 & 1.62 & 0 & $\mathbf{0 . 2 2}$ \\
\hline Mercury high pressure & 0.98 & 2.4 & 6 & $\mathbf{0 . 2 9}$ \\
\hline Sodium high pressure & 0.99 & 2.5 & -4.25 & $\mathbf{0 . 3}$ \\
\hline Sodium low pressure & 0.98 & 0.5 & 0 & $\mathbf{0 . 0 8}$ \\
\hline
\end{tabular}

It can be seen that apart from fluorescent and sodium low pressure lighting loads, other types of SSL can provide around $30 \%$ (based on nominal load rating) power reserve for $20 \%$ relaxation in non-critical load voltage. Low power reserve for fluorescent and sodium low pressure lighting loads is due to their weak dependence on voltage. Fluorescent lamps tend to behave as constant current loads for active power consumption while sodium low pressure lamp is between constant power and constant current type load. Reactive power of fluorescent lamp and mercury high pressure lamp is highly sensitive to terminal voltage $\left(V_{N C}\right)$ variation and has a positive slope, so the reactive demand of the load increases sharply with increase in $V_{N C}$. An opposite effect can be seen for sodium high pressure where the reactive demand decreases sharply with increase in $V_{N C}$ due the negative exponent $k q v$.

The total installed capacity of candidate static smart load in GB system is about $8.85 \mathrm{GW}(16.2 \%)$ assuming a conservative load factor of 0.6 for service sector loads and 0.8 for industrial sector loads [34]. Power reserve contribution from static smart loads thus amounts to $1.76 \mathrm{GW}$, which is around $3.22 \%$ of total GB load.

\section{E. Motor Smart Load (MSL) Candidates}

From Table I motor loads are selected from industrial and service sector and presented in Table IV along with what proportion could be considered as motor smart load (MSL). These loads are broadly classified into five application areas, e.g., space heating, cooling/ventilation, industrial motor, compressed air and refrigeration. Industrial motor has the largest share among motor type loads. Since no further classification data was available, motors under this category were equally split between large and small industrial motors.

Information available from motor drives vendor in GB suggests that at present, almost $80 \%$ of total industrial and service sector motor loads are direct on-line (DOL) motors. Out of the remaining $20 \%$, around $30 \%$ of the motor drives are for critical application, e.g., servo motor and high precision process loads. The remaining $14 \%$ of the total industrial and service sector motors can be potentially used as MSL. In Table IV, values in column (b) represent $14 \%$ of installed capacity (column (a)). Figures in column (c) are obtained from (6), based on the calculation method presented in Section III-B. The figures in column (d) show the available reserves in absolute units (GWs) which are obtained by multiplying the per unit reserve in column (c) with the corresponding smart load capacity in column (b). 
TABLE IV

MOTOR SMART LOAD (MSL) CANDIDATES

\begin{tabular}{|c|c|c|c|c|c|}
\hline \multirow{3}{*}{$\begin{array}{c}\text { Load } \\
\text { Sector }\end{array}$} & \multirow{2}{*}{$\begin{array}{c}\text { Load } \\
\text { Category }\end{array}$} & $\begin{array}{c}\text { Installed } \\
\text { Capacity }\end{array}$ & $\begin{array}{c}\text { MSL } \\
\text { capacity }\end{array}$ & \multicolumn{2}{c|}{$\begin{array}{c}\text { MSL } \\
\text { reserve }\end{array}$} \\
\cline { 3 - 6 } & & $(\mathrm{GW})$ & $(\mathrm{GW})$ & (p.u.) & $(\mathrm{GW})$ \\
\cline { 3 - 6 } & & (a) & (b) & (c) & (d) \\
\hline \hline \multirow{2}{*}{ Service } & Space heating & 2.65 & 0.37 & 0.425 & 0.16 \\
\cline { 3 - 6 } & Cooling/ventilation & 1.71 & 0.24 & 0.425 & 0.10 \\
\hline \multirow{5}{*}{ Industrial } & Space heating & 1.07 & 0.15 & 0.425 & 0.06 \\
\cline { 3 - 6 } & Large motor & 2.13 & 0.30 & 0.717 & 0.21 \\
\cline { 3 - 6 } & Small motor & 2.13 & 0.30 & 0.716 & 0.21 \\
\cline { 3 - 6 } & Compressed air & 1.20 & 0.17 & 0.717 & 0.12 \\
\cline { 3 - 6 } & Refrigeration & 0.64 & 0 & 0.692 & 0 \\
\hline \multicolumn{2}{|c|}{ Total motor load } & $\mathbf{1 1 . 5 3}$ & $\mathbf{1 . 5 2}$ & & $\mathbf{0 . 8 7}$ \\
\hline
\end{tabular}

TABLE V

InduCtion Motor PARAMETERS AND CALCULATED EXPONENTS

\begin{tabular}{|l|c|c|c|c|c|c|c|c|c|}
\hline \multicolumn{1}{|c|}{ Motor Type } & $R s$ & $X s$ & $X m$ & $R r$ & $X r$ & $A$ & $H$ & $L F$ & $k p f$ \\
\hline \hline $\begin{array}{c}\text { Industrial } \\
\text { Motor Small }\end{array}$ & 0.031 & 0.1 & 3.2 & 0.018 & 0.18 & 1 & 0.7 & 0.6 & $\mathbf{2 . 9 8}$ \\
\hline $\begin{array}{c}\text { Industrial } \\
\text { Motor Large }\end{array}$ & 0.013 & 0.067 & 3.8 & 0.009 & 0.17 & 1 & 1.5 & 0.8 & $\mathbf{2 . 9 9}$ \\
\hline Space Heating & 0.053 & 0.083 & 1.9 & 0.036 & 0.068 & 0.2 & 0.28 & 0.6 & $\mathbf{2 . 6 6}$ \\
\hline $\begin{array}{c}\text { Cooling and } \\
\text { Ventilation }\end{array}$ & 0.053 & 0.083 & 1.9 & 0.036 & 0.068 & 0.2 & 0.28 & 0.6 & $\mathbf{2 . 6 6}$ \\
\hline Compressed Air & 0.013 & 0.067 & 3.8 & 0.009 & 0.17 & 1 & 1.5 & 0.8 & $\mathbf{2 . 9 9}$ \\
\hline
\end{tabular}

\section{F. Power Reserve From Motor Smart Loads (MSL)}

The calculated exponents ( $k p f)$, based on the method presented in Section III-B, are shown in Table V for each type of motor load. The equivalent circuit parameters like stator resistance and reactance $\left(R_{s}, X_{S}\right)$, magnetizing reactance $\left(X_{m}\right)$, rotor resistance and reactance $\left(R_{r}, X_{r}\right)$ and other parameters like motor inertia $(H)$, load factor $(L F)$ and mechanical load speed-torque coefficient $(A)$ are taken from [34]. For calculation of $k p f$ generalized load speed-torque characteristic is used from [37]. Motor data from [34] suggests that industrial motors (both small and large) have similar load characteristic as compressor type load (compressed air). Hence, calculated $k p f$ values are similar for those.

Installed capacity of MSL accounts for $2.79 \%$ of the total GB load. Total power reserve from MSL amounts to $0.87 \mathrm{GW}$, which is around $1.59 \%$ of total GB load.

Taking into account the contributions from both SSL and MSL, the overall power reserve from smart loads is estimated to be $2.63 \mathrm{GW}$ which is $4.81 \%$ of total GB load. This is based on the conservative figures for load factors and distribution network node voltages. Estimated power reserve from smart loads is greater than the present primary (spinning) reserve $(1.8 \mathrm{GW})$ in the GB system. Even if only $50 \%$ of the estimated power reserve is practically realizable, smart loads could turn out to be effective for rapid frequency response provision.

\section{G. Simulation Results}

Time domain simulation results are presented to show the effectiveness of the smart loads. An under-frequency event was created at $20 \mathrm{~s}$ into the simulation by disconnecting a $2.0 \mathrm{GW}$ nuclear plant in zone 22 . This infeed loss is slightly larger than the present spinning reserve of the GB network and triggers the worst possible frequency event. Dynamic responses shown in Figs. 8 and 9 demonstrate that the smart loads improve frequency regulation and $\mathrm{RoCoF}$ which would be crucial in (a) disturbance bus 22

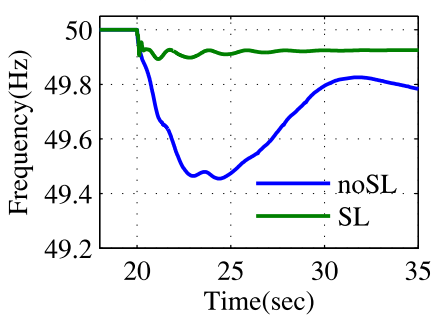

(c) disturbance bus 22
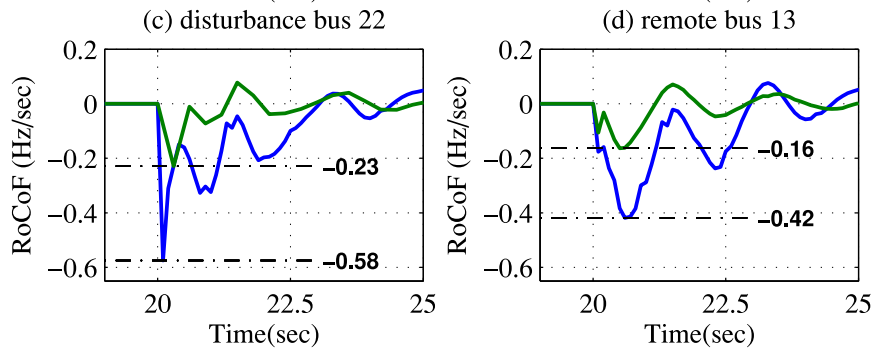

Fig. 8. Dynamic variation of grid frequency at bus 22 (a) and bus 13 (b); and RoCoF at bus 22 (c) and bus 13 (d) for present inertia scenario (base case). (a) disturbance bus 22

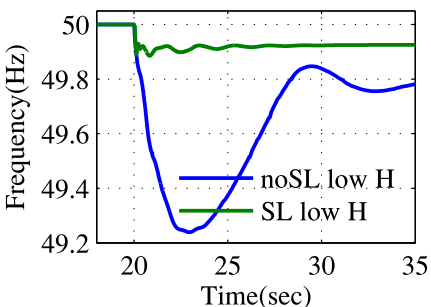

(c) disturbance bus 22

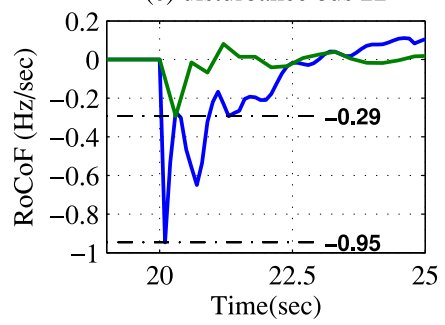

(b) remote bus 13

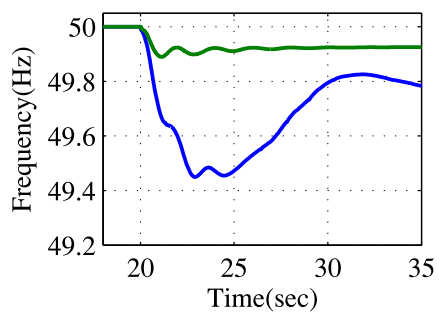

(d) remote bus 13

(d) remote bus 13

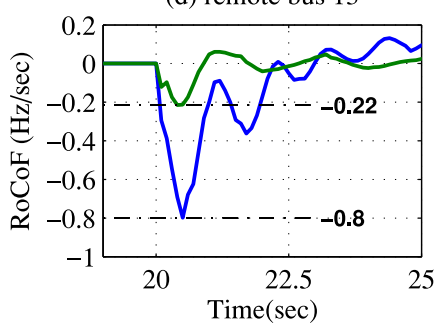

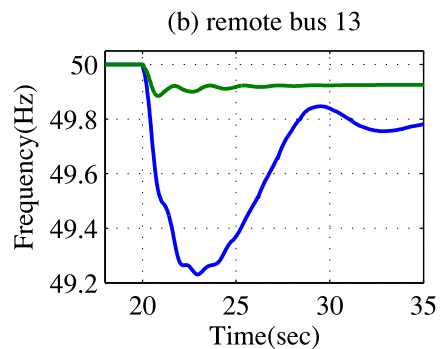

Fig. 9. Dynamic variation of grid frequency at bus 22 (a) and bus 13 (b); and RoCoF at bus 22 (c) and bus 13 (d) for future low inertia scenario.

future low inertia system [1]. Two different scenarios have been considered for this study: (a) nominal/present inertia and (b) future low inertia (50\% of present inertia).

Fig. 8(a)\&(b) compares the dynamic variation in frequency at disturbance bus and remote bus with normal loads (noSL) and smart loads (SL). Rapid frequency response offered by the aggregated smart loads help improve the frequency nadir and quickly stabilize the grid frequency.

Fig. 9 shows that with decrease in system inertia both frequency nadir and RoCoF become worse compared to present scenario for an identical disturbance. The RoCoF values are calculated using a $100 \mathrm{~ms}$ sliding window [38]. Under present condition RoCoF is around $0.4 \mathrm{~Hz} / \mathrm{s}$ as shown in Fig. 8(c)\&(d) which could increase up to $1 \mathrm{~Hz} / \mathrm{s}$ in future [1]. Smart loads are effective in improving the RoCoF and frequency nadir even for the low inertia scenario. 


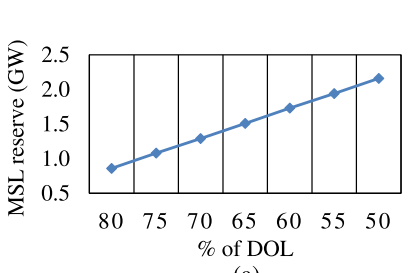

(a)

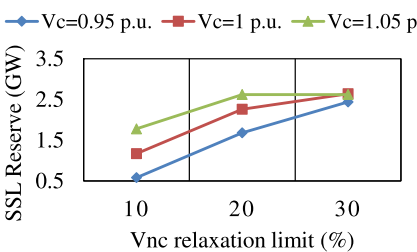

(c)

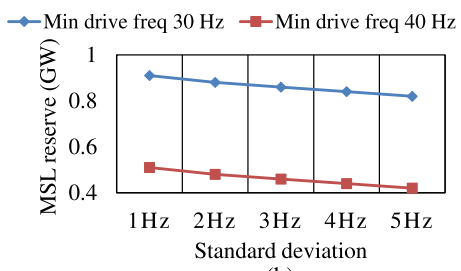

(b)

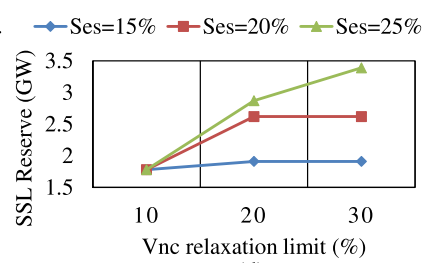

(d)
Fig. 10. Sensitivity of power reserve available from motor smart loads (MSL) to (a) percentage share of direct online (DOL) motor load (b) minimum permissible drive frequency and standard deviation of operating frequency of motor loads. Sensitivity of power reserve available from static smart loads (SSL) to (c) supply/mains voltage $\left(V_{C}\right)$ and (d) converter rating $\left(S_{E S}\right)$.

\section{H. Sensitivity Analysis}

Several parameters were assumed while estimating the power reserve from smart loads in Sections IV-D and IV-F. Results of sensitivity analysis around those assumed parameters are presented in this section. Proportion of drive controlled motor loads is expected to increase in future for improved performance and efficiency. Fig. 10 (a) shows the power reserve available from MSL for increase in drive controlled motors, i.e., reduction in DOL motors from about $80 \%$ at present down to about $50 \%$ in the future. Available power reserve increases significantly with a maximum of around $2.0 \mathrm{GW}$.

Power reserve from drive based motor loads depend on the minimum permissible frequency set point $\left(f_{d r}\right)$ and the operating frequency $\left(f_{i}\right)$ at the time of disturbance. Fig. 10 (b) shows the power reserve for different values of standard deviation and minimum drive frequency. The operating frequencies of the motor loads connected to a node are considered to be normally distributed around a mean value of $50 \mathrm{~Hz}$. The standard deviation is varied from $1 \mathrm{~Hz}$ to $5 \mathrm{~Hz}$ for two separate minimum drive frequencies $-30 \mathrm{~Hz}$ and $40 \mathrm{~Hz}$. Since the minimum drive frequency of all the motors are fixed at either 30 or $40 \mathrm{~Hz}$, the aggregated power reserve reduces with increase in standard deviation.

The capability of SSL depends on several factors including the rating of the converter, allowable voltage variation across the non-critical load $\left(V_{N C}\right)$, supply mains voltage $\left(V_{C}\right)$ etc. Assuming the converter rating is limited to $20 \%$ of the non-critical load rating, the impact of change in $V_{C}$ and $V_{N C}$ relaxation limit on the power reserve available from SSL is shown in Fig. 10 (c). Higher $V_{C}$ and $V_{N C}$ relaxation limit increases the power reserve from SSL. Any frequency disturbance resulting in terminal voltage increase will positively contribute towards the SSL capability. However, power reserve from SSL increase with $V_{C}$ and $V_{N C}$ (relaxation limit) only up to a certain point beyond which it gets limited by the converter rating.

Fig. 10 (d) shows the power reserve from SSL for different $V_{N C}$ relaxation limits and converter ratings $\left(S_{E S}\right)$ considering
$V_{C}=1.05$ pu. Comparison with Fig. 10 (c) clearly suggests that larger power reserve is obtainable with higher converter ratings.

\section{CONCLUSION}

In this paper, the effectiveness of smart loads for rapid frequency response is demonstrated through a case study on the Great Britain (GB) power system. The total power reserve available from the smart loads in GB system was found to be about $2.6 \mathrm{GW}$ which is more than the present spinning reserve $(1.8 \mathrm{GW})$. A short-term voltage tolerance of $20 \%$ is assumed for the static non-critical loads to demonstrate the concept. In practice, this tolerance could be tighter. Nonetheless, the SLs could collectively provide sufficient reserve to complement (or reduce the need for) fast reserve provision from energy storage etc. Simulations show that the smart loads are able to ensure acceptable frequency deviation and its rate of change (RoCoF) following a large infeed loss. For static smart loads (SSLs), additional investment in power electronic interface is necessary to utilize the power-voltage dependence of appropriate loads. For drive controlled motors, subtle modification in the control circuitry can be used to provide power reserve with no additional power electronics. Reserve from such smart motor loads (MSLs) will increase significantly in future due to larger proportion of drive controlled motors.

One concern is that most of the candidate smart loads are not operational on a continuous (24/7) basis which calls for power reserve calculation on an hourly basis. Due to nonavailability of accurate hourly power consumption data for individual load types in the GB system, such results could not be reported in this paper. Our present work focuses on using the recorded power profiles at MV substations for load disaggregation and thus quantifying the power reserve on an hourly (or half-hourly) basis.

\section{REFERENCES}

[1] National Grid. (2014). System Operability Framework 2014. [Online]. Available: http://www2.nationalgrid.com/UK/ Industry-information/Future-of-Energy/System-Operability-Framework/

[2] G. Stein, "Frequency response technical sub-group report," Frequency Response Tech. Sub-Group, Nat. Grid, Warwick, U.K., Working Group Rep., 2011. [Online]. Available: http://www.nationalgrid.com/NR/rdonlyres/2AFD4C05-E169-4636BF02-EDC67F80F9C2/50090/FRTSGGroupReportFinal.pdf

[3] P. Palensky and D. Dietrich, "Demand side management: Demand response, intelligent energy systems, and smart loads," IEEE Trans. Ind. Informat., vol. 7, no. 3, pp. 381-388, Aug. 2011.

[4] M. Parvania and M. Fotuhi-Firuzabad, "Demand response scheduling by stochastic SCUC," IEEE Trans. Smart Grid, vol. 1, no. 1, pp. 89-98, Jun. 2010.

[5] M. A. A. Pedrasa, T. D. Spooner, and I. F. MacGill, "Scheduling of demand side resources using binary particle swarm optimization," IEEE Trans. Power Syst., vol. 24, no. 3, pp. 1173-1181, Aug. 2009.

[6] A. H. Mohsenian-Rad, V. W. S. Wong, J. Jatskevich, R. Schober, and A. Leon-Garcia, "Autonomous demand-side management based on game-theoretic energy consumption scheduling for the future smart grid," IEEE Trans. Smart Grid, vol. 1, no. 3, pp. 320-331, Dec. 2010.

[7] J. A. Short, D. G. Infield, and L. L. Freris, "Stabilization of grid frequency through dynamic demand control," IEEE Trans. Power Syst., vol. 22, no. 3, pp. 1284-1293, Aug. 2007.

[8] D. Angeli and P. A. Kountouriotis, "A stochastic approach to 'dynamicdemand' refrigerator control," IEEE Trans. Control Syst. Technol., vol. 20, no. 3, pp. 581-592, May 2012. 
[9] M. Aunedi, P. A. Kountouriotis, J. E. O. Calderon, D. Angeli, and G. Strbac, "Economic and environmental benefits of dynamic demand in providing frequency regulation," IEEE Trans. Smart Grid, vol. 4, no. 4, pp. 2036-2048, Dec. 2013.

[10] H. Liu, Z. Hu, Y. Song, and J. Lin, "Decentralized vehicle-to-grid control for primary frequency regulation considering charging demands," IEEE Trans. Power Syst., vol. 28, no. 3, pp. 3480-3489, Aug. 2013.

[11] C. T. Li, C. Ahn, H. Peng, and J. Sun, "Synergistic control of plug-in vehicle charging and wind power scheduling," IEEE Trans. Power Syst., vol. 28, no. 2, pp. 1113-1121, May 2013.

[12] M. Świerczyński, D. I. Stroe, A. I. Stan, and R. Teodorescu, "Primary frequency regulation with li-ion battery energy storage system: A case study for Denmark," in Proc. ECCE Asia Downunder (ECCE Asia), Melbourne, VIC, Australia, 2013, pp. 487-492.

[13] M. Świerczyński et al., "Field tests experience from $1.6 \mathrm{mw} / 400 \mathrm{kwh}$ li-ion battery energy storage system providing primary frequency regulation service," in Proc. Innov. Smart Grid Technol. Europe (ISGT EUROPE), Lyngby, Denmark, 2013, pp. 1-5.

[14] S. Y. R. Hui, C. K. Lee, and F. F. Wu, "Electric springs-A new smart grid technology," IEEE Trans. Smart Grid, vol. 3, no. 3, pp. 1552-1561, Sep. 2012.

[15] N. R. Chaudhuri, C. K. Lee, B. Chaudhuri, and S. Y. R. Hui, "Dynamic modeling of electric springs," IEEE Trans. Smart Grid, vol. 5, no. 5, pp. 2450-2458, Sep. 2014.

[16] S. C. Tan, C. K. Lee, and S. Y. R. Hui, "General steady-state analysis and control principle of electric springs with active and reactive power compensations," IEEE Trans. Power Electron., vol. 28, no. 8, pp. 3958-3969, Aug. 2013.

[17] C. K. Lee and S. Y. R. Hui, "Reduction of energy storage requirements in future smart grid using electric springs," IEEE Trans. Smart Grid, vol. 4, no. 3, pp. 1282-1288, Sep. 2013.

[18] C. K. Lee, N. R. Chaudhuri, B. Chaudhuri, and S. Y. R. Hui, "Droop control of distributed electric springs for stabilizing future power grid," IEEE Trans. Smart Grid, vol. 4, no. 3, pp. 1558-1566, Sep. 2013.

[19] C. K. Lee, B. Chaudhuri, and S. Y. R. Hui, "Hardware and control implementation of electric springs for stabilizing future smart grid with intermittent renewable energy sources," IEEE J. Emerg. Sel. Topics Power Electron., vol. 1, no. 1, pp. 18-27, Mar. 2013.

[20] X. Luo et al., "Distributed voltage control with electric springs: Comparison with STATCOM," IEEE Trans. Smart Grid, vol. 6, no. 1, pp. 209-219, Jan. 2015.

[21] Z. Akhtar, B. Chaudhuri, and S. Y. R. Hui, "Primary frequency control contribution from smart loads using reactive compensation," IEEE Trans. Smart Grid, vol. 6, no. 5, pp. 2356-2365, Sep. 2015.

[22] C. Zhao, U. Topcu, N. Li, and S. Low, "Design and stability of loadside primary frequency control in power systems," IEEE Trans. Autom. Control, vol. 59, no. 5, pp. 1177-1189, May 2014.

[23] A. Molina-Garcia, F. Bouffard, and D. S. Kirschen, "Decentralized demand-side contribution to primary frequency control," IEEE Trans. Power Syst., vol. 26, no. 1, pp. 411-419, Feb. 2011

[24] Department of Energy and Climate Change. (2014). Energy Consumption in the UK Overall Data Tables 2014 Update. [Online]. Available: https://www.gov.uk/government/statistics/ energy-consumption-in-the-uk

[25] A. Hughes and B. Drury, Electric Motors and Drives, 4th ed. Amsterdam, The Netherlands: Elsevier, 2013.

[26] A. Ballanti and L. Ochoa. (2015). WP2 Part A-Final Report 'Off-Line Capability Assessment.' [Online]. Available: http://www.enwl.co.uk/docs/default-source/class-documents/offlinedemand-response-capability-assessment-final-report.pdf?sfvrsn=4

[27] W. Price, H. Chiang, H. Clark, and C. Concordia, "Load representation for dynamic performance analysis," IEEE Trans. Power Syst., vol. 8, no. 2, pp. 472-482, May 1993.

[28] J. V. Milanovic, K. Yamashita, S. M. Villanueva, S. Ž. Djoki, and L. M. Korunović, "International industry practice on power system load modeling," IEEE Trans. Power Syst., vol. 28, no. 3, pp. 3038-3046, Aug. 2013.

[29] K. R. Amarnath, "Variable refrigerant flow: Demonstration of efficient space conditioning technology using variable speed drives," in Proc. 13th Eur. Conf. Power Electron. Appl., Barcelona, Spain, 2009, pp. 1-10.

[30] K. Tomiyama, J. P. Daniel, and S. Ihara, "Modeling air conditioner load for power system studies," IEEE Trans. Power Syst., vol. 13, no. 2, pp. 414-421, May 1998.

[31] Department of Energy and Climate Change. (2014). Energy Consumption in the UK Service Sector Data Tables 2014 Update. [Online]. Available: https://www.gov.uk/government/statistics/ energy-consumption-in-the-uk
[32] C. K. Lee, S. Li, and S. Y. R. Hui, "A design methodology for smart LED lighting systems powered by weakly regulated renewable power grids," IEEE Trans. Smart Grid, vol. 2, no. 3, pp. 548-554, Sep. 2011.

[33] K. Linden and I. Segerqvist. (1992). Modelling of Load Devices and Studying Load/System Characteristics. [Online]. Available: http://webfiles.portal.chalmers.se/et/Lic/Linden\%26SegerqvistLic.pdf

[34] W. Price, K. Wirgau, A. Murdoch, and F. Nozari. (1987). Load Modeling for Power Flow and Transient Stability Computer Studies Volume 2. [Online]. Available: http://www.epri.com/abstracts/Pages/ ProductAbstract.aspx?ProductId=EL-5003-CCMV2

[35] L. M. Hajagos and B. Danai, "Laboratory measurements and models of modern loads and their effect on voltage stability studies," IEEE Trans. Power Syst., vol. 13, no. 2, pp. 584-592, May 1998.

[36] N. Lu, Y. Xie, Z. Huang, F. Puyleart, and S. Yang, "Load component database of household appliances and small office equipment," in Proc. 21st Century IEEE Power Energy Soc. Gen. Meeting Convers. Del. Elect. Energy (PES), Pittsburgh, PA, USA, 2008, pp. 1-5.

[37] W. Price, C. Taylor, G. Rogers, C. Concordia, and K. Srinivasan, "Standard load models for power flow and dynamic performance simulation," IEEE Trans. Power Syst., vol. 10, no. 3, pp. 1302-1313, Aug. 1995.

[38] PPA Energy. Rate of Change of Frequency (ROCOF) Final Report 2013. Accessed on Feb. 17, 2015. [Online]. Available: http://www.cer.ie/ docs/000260/cer13143-(a)-ppa-tnei-rocof-final-report.pdf

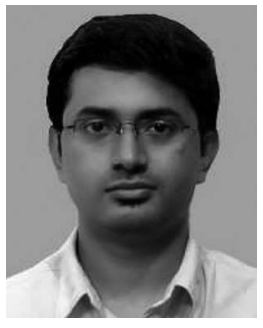

Diptargha Chakravorty (S'14) received the M.Tech. degree in energy engineering from the Indian Institute of Technology Delhi, India, in 2012. He is currently pursuing the Ph.D. degree with Imperial College London, U.K. He was a Research Assistant at the Institute of Electrical Power Systems and High Voltage Engineering, Technische Universität Dresden, Germany, for one year. His research interests include power transmission systems, demand side management, renewable energy, and power quality.

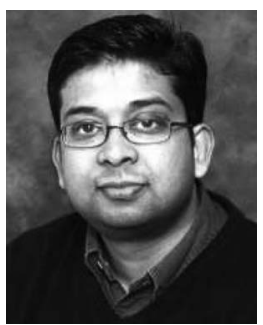

Balarko Chaudhuri (M'06-SM'06) received the Ph.D. degree in electrical and electronic engineering from Imperial College London, U.K., in 2005. His research interests include electric power transmission systems, control theory, smart grids, and renewable energy. He is an Associate Editor of the IEEE SYSTEMS JOURNAL and Control Engineering Practice. He is a member of the IET and Cigre.

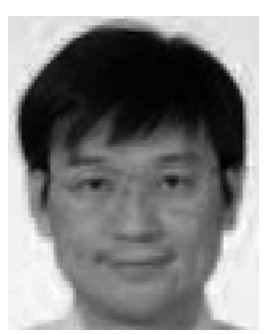

Shu Yuen Ron Hui (M'87-SM'94-F'03) received the B.Sc. (Hons.) degree in electrical and electronic engineering from the University of Birmingham, Birmingham, U.K., in 1984, and the D.I.C. and Ph.D. degrees from Imperial College London, London, U.K., in 1987. He currently holds the Philip Wong Wilson Wong Chair Professorship with the University of Hong Kong, Hong Kong. Since 2010, he has concurrently held a part-time Chair Professorship in Power Electronics at Imperial College London. He has published over 200 technical papers, including about 170 refereed journal publications and book chapters. Over 55 of his patents have been adopted by industry. He was the recipient of the IEEE Rudolf Chope Research and Development Award from the IEEE Industrial Electronics Society, the Achievement Medal (Crompton Medal) from the Institution of Engineering and Technology in 2010, and the 2015 IEEE William E. Newell Power Electronics Award. He is an Associate Editor of the IEEE TRANSACTIONS ON POWER ElECTRONICS and the IEEE TRANSACTIONS ON INDUSTRIAL ELECTRONICS. He is a fellow of the Australian Academy of Technological Sciences and Engineering. 